\title{
Contribution of Hypothalamic-Pituitary-Adrenal Activity and Environmental Stress to Vulnerability for Smoking in Adolescents
}

\author{
Uma Rao*,', Constance L Hammen ${ }^{2,3}$, Edythe D London ${ }^{3,4}$ and Russell E Poland ${ }^{5}$ \\ 'Department of Psychiatry, UT Southwestern Medical Center, Dallas, TX, USA; ²Department of Psychology, University of California, Los Angeles, \\ CA, USA; ${ }^{3}$ Department of Psychiatry and Biobehavioral Sciences, University of California, Los Angeles, CA, USA; ${ }^{4}$ Department of Molecular and \\ Medical Pharmacology, University of California, Los Angeles, CA, USA; ${ }^{5}$ Department of Psychiatry, Meharry Medical College, Nashville, TN, USA
}

\begin{abstract}
Although tobacco smoking, which has been linked to depression, is a major public health problem, little is known about the neurobiological factors that confer vulnerability to smoking in youngsters and the effects of adolescent smoking on the course of depression. This study examined whether hypothalamic-pituitary-adrenal (HPA) activity and stressful life experiences are related to smoking behavior in depressed and non-depressed adolescents, and whether smoking predicts a worsening course of depression. Smoking history and stressful experiences were assessed in $15 \mathrm{I}$ adolescents (48 with no personal or family history of psychiatric disorder, 48 with no psychiatric history, but at high risk for depression by virtue of parental depression, and 55 with current major depressive disorder). Evening salivary cortisol and nocturnal urinary-free cortisol were measured for three consecutive evenings. The participants were then followed at regular intervals for up to 5 years to assess smoking history, clinical course of depression and stressful experiences during the follow-up period. Increased evening/night-time cortisol levels were associated with both initiation and persistence of smoking during follow-up. Stressful life experiences further increased the risk for smoking in depressed as well as non-depressed youth. Smoking was also associated with a higher frequency of depressive episodes during follow-up. A model that included stressful experiences and cortisol levels reduced the contribution of smoking per se to depression. High evening/night-time cortisol level appears to be a vulnerability marker for smoking in adolescents, with stressful experiences further increasing the risk for smoking in vulnerable youth. High evening/night-time cortisol levels and stressful experiences accounted, at least partially, for the association between depressive illness and smoking behavior.

Neuropsychopharmacology (2009) 34, 272 I-2732; doi: 10.1038/npp.2009.I I2; published online 19 August 2009
\end{abstract}

Keywords: adolescents; depression; HPA axis; smoking; stress; vulnerability

\section{INTRODUCTION}

Cigarette smoking is a substantial source of morbidity and premature mortality (Centers for Disease Control and Prevention, 2002; Lopez et al, 2006; Max, 2001). Almost all tobacco use begins during adolescence, and despite decades of public health efforts, millions of adolescents initiate and continue to smoke (Botello-Harbaum et al, 2009; Centers for Disease Control and Prevention, 2002, 2006; Johnston et al, 2009). Generating knowledge of the factors that promote smoking in adolescents, therefore, is a high priority from a public health perspective.

Prospective studies in adolescents and adults have shown that depression increases the risk for smoking, and vice versa (Breslau et al, 1998; Brown et al, 1996; Choi et al, 1997;

*Correspondence: Dr U Rao, Department of Psychiatry, UT Southwestern Medical Center, 5323 Harry Hines Boulevard, Dallas, TX 75390-9|0I, USA. Tel: + I 214648 5288, Fax: + I 2146485242 , E-mail: uma.rao@utsouthwestern.edu

Received 10 June 2009; revised 16 July 2009; accepted 20 July 2009
Fergusson et al, 2003; Klungsøyr et al, 2006; Munafò et al, 2008; Patton et al, 1998; Steuber and Danner, 2006; Windle and Windle, 2001). In some studies, adult smokers with a history of depression were less likely to succeed in smoking cessation, and were more likely to experience severe withdrawal symptoms during attempts to quit, compared with non-depressed smokers (Anda et al, 1990; Berlin et al, 1997; Breslau et al, 1992; Covey et al, 1990; Ginsberg et al, 1995; Glassman et al, 2001; John et al, 2004). Smoking cessation also might trigger relapse of depressive episodes in smokers with a history of depression (Borrelli et al, 1996; Breslau and Johnson, 2000; Covey et al, 1997; Khaled et al, 2009; Tsoh et al, 2000).

This study was undertaken to examine biopsychosocial factors associated with initiation and persistence of smoking in depressed and non-depressed adolescents. Environmental stress and hypothalamic-pituitary-adrenal (HPA) activity were selected as study variables for the following reasons. Stress has been associated with smoking initiation (Byrne and Mazanov, 2003; Koval et al, 2000; Nichter et al, 1997), as well as the transition to regular smoking (Orlando 
et al, 2001; Siqueira et al, 2000). Research findings suggest that high responsivity of the brain stress systems (including the HPA axis) moderates the effects of exposure to stress on drug-seeking behavior (Koob and Kreek, 2007; Rao and Chen, 2008; Sinha, 2008; Zislis et al, 2007). There is also an extensive literature demonstrating a relationship between HPA status and nicotine administration in animals and adult humans (al'Absi, 2006; Berlin, 2009; Lovallo, 2006; Mendelson et al, 2008; Rohleder and Kirschbaum, 2006; Sidhartha et al, 2009). Stressful life experiences and abnormalities in the HPA system also have been noted in numerous investigations of depression (Hammen, 2005; Holsboer and Ising, 2008; Meyer et al, 2001). We, therefore, posed the following hypotheses: (1) that HPA activity measured at baseline would be positively correlated with likelihood of smoking initiation and persistent smoking during prospective follow-up, (2) that recent stressful life experiences would further increase the risk for smoking in individuals who have high HPA activity, and (3) that the association between depressive disorder and smoking might be explained partly by stressful life experiences and high HPA activity.

\section{MATERIALS AND METHODS}

The data reported here are part of a larger study on the development and course of depression in adolescents, as well as the relationship between depression and substance use disorders (Rao et al, 2009a, b).

\section{Participants}

Subjects were recruited from the outpatient clinics at university-affiliated medical centers and through advertisements in local newspapers. After receiving a complete explanation of the procedures, all adolescents signed a written assent form, and parents gave written informed consent to participate in the research protocol, which was approved by institutional review boards at the University of California at Los Angeles and associated medical institutions. The participants for the study included 55 adolescents with depression, 48 adolescents at high risk for developing depression, and 48 normal controls.

The depressed subjects met criteria for major depressive disorder according to DSM-IV criteria (American Psychiatric Association, 1994), with a minimum duration of 4 weeks and a score of $\geqslant 15$ on the first 17 items of the Hamilton Depression Rating Scale (HDRS; Hamilton, 1960). Adolescents with a current or prior history of mania, hypomania, substance use disorder symptoms, schizophrenia, schizoaffective disorder, or autism were excluded from the study. Subjects were also excluded if there was a family history of bipolar disorder. All subjects were free from antidepressant drugs and other psychotropic agents for at least 4 weeks (8 weeks for fluoxetine). The normal and highrisk control subjects were free from any psychopathology, including depression, over their lifetime. In addition, the high-risk control subjects had at least one biological parent with a history of unipolar major depressive disorder that required treatment. Subjects were excluded from the normal control group if any first-degree relative had history of a psychiatric disorder. All participants were medically healthy and free from alcohol or illicit drug use, as determined by physical examination, full chemistry panel, thyroid function tests, electrocardiogram, and urine drug screens.

\section{Diagnostic Evaluation}

The diagnosis of major depressive disorder and other psychiatric disorders was done using the Schedule for Affective Disorders and Schizophrenia for School-Age Children - the Present and Lifetime Version (K-SADS-PL; Kaufman et al, 1996). The K-SADS-PL is a semistructured interview designed to ascertain present and lifetime history of psychiatric illness according to DSM-IV criteria. Probes and objective criteria are provided for individual symptoms at both diagnostic and subthreshold levels. Interrater and test-retest reliability have been established, as well as convergent and discriminant validity (Kaufman et al, 1997). The K-SADS-PL was administered separately to the parent and the adolescent, and both were re-interviewed to resolve any discrepancies. Summary scores were tabulated on the basis of the information obtained from both informants. The children's global assessment scale (CGAS), a global psychosocial functioning measure, was also completed (Shaffer et al, 1983). The adolescents completed the beck depression inventory (BDI) for self-assessment of depression severity (Beck et al, 1961).

\section{Family Psychopathology}

The Family History-Research Diagnostic Criteria (FHRDC), a semistructured instrument, was used for the evaluation of psychiatric disorders in family members (Andreasen et al, 1977). One parent was interviewed regarding major psychiatric disorders over lifetime in all first-degree relatives of the adolescent subject. The FH-RDC is sensitive for obtaining information from knowledgeable relatives (Thompson et al, 1982).

\section{Smoking Behavior}

Information was obtained on current and past smoking history, including number of cigarettes, frequency, as well as number of attempt(s) to quit and duration of smoke-free period(s). Other forms of nicotine use were also noted. At the time of recruitment, to specifically identify nonsmokers, any subject who reported smoking one or more cigarettes over his/her lifetime was considered a smoker. Smokers were administered the adolescent version of the Fagerstrõm tolerance questionnaire (FTQ) (Fagerström, 1978), which measures behavioral responses that are suggestive of nicotine dependence. The adolescent version of the FTQ has 7 items, and scores range from 0 to 9 (Prokhorov et al, 1996). A score $\leqslant 2$ suggests no evidence of nicotine dependence, and values ranging from 3 to 5 are considered to reflect moderate dependence. A score of $\geqslant 6$ on the FTQ indicates a high level of nicotine dependence. In earlier research, nicotine dependence symptoms on the FTQ correlated with cotinine (a metabolite of nicotine) levels (Prokhorov et al, 2000). 


\section{Stressful Life Experiences}

To obtain information on recent stressful life experiences, a semistructured interview developed by a member of our team was used (Hammen et al, 1995). This interview is based on the contextual threat assessment (Brown and Harris, 1978). Inter-rater reliability has been established for this instrument (Hammen and Brennan, 2001; Hammen et al, 1995). Using the list developed by Paykel and Mangen (1980), and adapted for an adolescent population, the participants were systematically probed about the occurrence and timing of particular life events specifically to obtain objective features of the events and circumstances. For the baseline assessment, the time frame for events included the earlier 6 months. Narrative summaries of the event and the surrounding context were presented to a group of trained raters on the instrument. To obtain ratings of severity of stressors that were not distorted by participants' depressive symptoms or misattribution of the meaning of the stressors, the raters were blind to the subject's diagnostic status and perception of stress. Consensus group ratings were given for the degree of stress for each event $(1=$ not at all stressful, and $5=$ extremely stressful), and whether the event was a positive, neutral or negative experience under the given circumstances. To be included in the analysis, an event was required to have an impact for at least 1 day and to involve at least mild stress. Only events that were considered negative were included in the analyses. Symptom-related events were not scored.

\section{HPA Measures}

Each subject participated in a 3-night, sleep-neuroendocrine study in the laboratory. Before these studies, sleepwake schedules were regulated for at least 1 week, with participants going to bed between 10:00 to 11:00 p.m. and waking between 6:30 to 7:30 a.m. The sleep-wake schedule was confirmed through diary and actigraphy. The participants were free from alcohol/illicit drug use at the time of HPA studies (confirmed by urine drug screens). Only evening and night-time cortisol values were used to measure HPA activity. Subjects arrived in the laboratory by 8:00 p.m., and they were instructed to have dinner at least an hour before arrival in the laboratory. Immediately after arriving in the laboratory, the participants were asked to lie down and were allowed only non-caloric fluids before and during the saliva collection. Saliva samples were obtained at half-hour intervals from 8:30 to 9:30 p.m. Subjects were asked to void urine before switching off the lights. After lights out, all urine voided during the night (including the sample obtained immediately upon awakening) was collected.

The choice of evening and nocturnal cortisol samples as study measures was based on prior research in youngsters, indicating that cortisol sampling during this time period, when the HPA axis is normally quiescent, was most robust in discriminating depressed adolescents from controls and also in predicting the longitudinal clinical course (Dahl et al, 1991; Goodyer et al, 1997, 2001; Rao et al, 1996, 1999). To prevent potential sleep disruption, salivary and urinary samples, instead of plasma samples, were collected to assess HPA activity. A radioimmunoassay procedure was used for the cortisol assays (McCracken and Poland, 1989; Poland and Rubin, 1982). Urinary-free cortisol values were expressed as concentration and total amount excreted. All samples from any individual subject were analyzed in the same assay. Low, medium, and high cortisol pools were re-analyzed in each assay to assess intra- and inter-assay variability. The intra- and inter-assay coefficients of variation for the assays were $<10 \%$.

\section{Follow-up Evaluation}

After the initial assessments, the participants were followed longitudinally at 6-month intervals in the first year and yearly thereafter, for up to 5 years, to obtain information on smoking history and the clinical course of depression and other psychiatric disorders. Any youngster who smoked at least 4 days/week for $>1$ week during follow-up was considered a smoker. This definition is consistent with a regular smoker; smoking often but still not frequent enough to be considered a daily/established smoker (Mayhew et al, 2000). Development of a depressive episode was defined as a rating of 5 on the psychiatric status rating (PSR) component of the longitudinal interval follow-up evaluation (LIFE) for a minimum 4-week duration. Remission from a depressive episode was defined as a rating of 2 for $\geqslant 12$ weeks on the PSR. Recurrence was defined as a PSR rating of $\geqslant 5$ for 4 or more weeks with a minimum duration of 12 weeks between episodes. The conventional criterion for remission is 8 weeks, and the minimum duration for recurrent depressive episode is 2 weeks (Frank et al, 1991). In this study, stringent criteria were used for remission and recurrence to ensure stability of symptoms because depressive symptoms in youngsters tend to be more variable, with greater heterogeneity in clinical response and course, than adults (Kaufman et al, 2001; Rao and Chen, 2009). The LIFE is a semistructured instrument used for charting the clinical course of depression and other psychiatric disorders during longitudinal follow-up (Shapiro and Keller, 1979). The PSR is a 6-point scale providing information on the severity of depressive symptom profile.

Information from the diagnostic assessments was presented to an independent clinician (UR) 'blind' to the diagnostic status, stressful life events, and HPA status. Final diagnosis was based on consensus ratings. Assessment of stressful experiences during the follow-up period was similar to the method used during initial evaluation. Time frame for the events included the period since the last interview. Ratings for the magnitude of stress occurred blind to information from the diagnostic and HPA assessment.

\section{Primary Dependent and Independent Variables}

The primary outcome measure was onset of smoking during follow-up. The primary independent variables included HPA activity (evening salivary and nocturnal urinary-free cortisol levels) and stressful experiences. For salivary cortisol, average values of the three samples on each night were determined and then a single mean value was obtained across the 3 nights. For nocturnal urinary-free cortisol samples, a single mean value was obtained across the 3 nights. Timelines were generated, charting the onset of 
smoking behavior and stressful life events. For each participant who began smoking during follow-up, the total episodic stress score for the 3 months preceding smoking initiation was computed. Each non-smoker was paired with a smoker based on demographic and clinical information, and the episodic stress that he/she experienced in the corresponding 3 months was tabulated. This method was adopted instead of using a random 3-month period because events were not evenly distributed across the 5 years due to developmentally expected events (eg high school graduation and transition to college occurs in older adolescents). Secondary outcome measures included the onset of a depressive episode during follow-up (in normal and highrisk controls), and recurrence of a depressive episode (in the depressed group). Smoking status during follow-up, HPA activity (evening salivary and nocturnal urinary-free cortisol levels) at baseline and stressful experiences during follow-up were the independent variables.

\section{Statistical Analysis}

For all summary variables, data were examined for normality using the Shapiro-Wilk's W statistic (Shapiro and Wilk, 1965). Cortisol variables were log-transformed and the psychosocial measures were standardized before the application of statistical tests for significance. For group comparisons, the $\chi^{2}$ was used to analyze categorical variables and analysis of variance for continuous variables. Correlation procedures were used to examine associations between variables. Cox regression, with appropriate covariates, was used to compute the probability of smoking during follow-up. Cortisol measures obtained at baseline, stress score in the 3 months preceding the onset of smoking and the interaction term (HPA $\times$ stress) were used as independent variables. The relationships among depression, smoking, HPA activity and stress were examined through the logistic regression procedure. All analyses were twotailed, and the $\alpha$ was set at 0.05 .

\section{RESULTS}

\section{Demographic, Clinical, and Biological Parameters at Baseline}

Demographic, clinical, and biological features of the three groups of adolescents are outlined in Table 1. The groups did not differ significantly with respect to age, gender, or ethnicity. High-risk and depressed groups had significantly lower socioeconomic score than normal controls. Depressed adolescents scored significantly higher on the BDI, HDRS, and stressful experiences, but lower on CGAS, than both comparison groups. The groups did not differ significantly with respect to smoking status or salivary cortisol, but depressed youth had higher nocturnal urinary-free cortisol than normal controls, whereas the high-risk subjects had intermediate levels.

\section{Follow-up Information}

Three initially normal controls, four high-risk subjects and four depressed adolescents only were assessed at intake and did not complete any follow-up evaluations. Subjects who did not participate in follow-up assessments did not differ significantly from those with follow-up information on any demographic or clinical characteristics. Recruitment did not occur simultaneously and, therefore, not all subjects were studied longitudinally for the same period of time. Of the 140 adolescents who had follow-up information, 9.3\% were followed for 2 years, $19.3 \%$ for 3 years, $31.4 \%$ for 4 years, and $40.0 \%$ for 5 years. The three groups were comparable on the mean follow-up interval (mean follow-up inter$\mathrm{val}=3.6$ years, $\mathrm{SD}=1.0)$.

\section{Initiation of Smoking}

Of a total of 140 adolescents who had follow-up information, $109(77.9 \%)$ had no prior smoking history at intake. Of these 109 participants, 21 (19.3\%) initiated smoking during the study. The mean FTQ score in the smokers was 3.7 $(\mathrm{SD}=1.3$; range, 2.0-6.5). On the basis of the FTQ score, four $(19.0 \%)$ showed no evidence of nicotine dependence, $15(71.4 \%)$ had moderate level of dependence and two (9.5\%) manifested high level of dependence. Severity of nicotine dependence was comparable among the three diagnostic groups. Demographic and clinical characteristics of subjects who initiated smoking and those who never smoked are provided in Table 2. The groups did not differ significantly on any demographic or clinical variables but there was a trend for adolescents who initiated smoking to have a longer follow-up period compared with nonsmokers.

Of a total of 37 depressed youth with no prior smoking history at intake, 6/13 (46.2\%) participants with comorbid anxiety disorder initiated smoking compared with 3/24 $(12.5 \%)$ subjects without anxiety disorder (FET, $p=0.04)$. Of 5 youth with comorbid disruptive disorder, 1 (20\%) initiated smoking compared with 8/32 (25.0\%) without disruptive disorder (FET, NS).

\section{Effects of HPA Activity and Stress on Smoking Initiation}

There was a high correlation among the three cortisol measures $(r=0.66$ between salivary cortisol and urinaryfree cortisol concentration; $r=0.62$ between salivary cortisol and total urinary cortisol; and $r=0.94$ between the two urinary cortisol measures). Hence, a composite measure of HPA activity was derived by taking a mean of the three measures.

Among adolescents who had no prior smoking history at intake, after accounting for differential follow-up period, higher evening/night-time cortisol levels predicted initiation of smoking (see Table 3). Stressful experiences also made an independent contribution to the initiation of smoking. The analyses were run separately in depressed adolescents and control subjects (combining normal and high-risk groups), and the same pattern emerged even after controlling for comorbid disorders in the depressed cohort.

For the purpose of graphical representation, the sample was stratified into four groups based on a median split of HPA activity (evening/night-time cortisol levels) and stress at follow-up: low HPA activity-low stress $(n=39)$; low HPA activity-high stress $(n=22)$; high HPA activity-low stress $(n=22)$; and high HPA activity-high stress $(n=26)$. These groups were then compared on the probability of smoking 
Table I Baseline Demographic, Clinical, and Biological Parameters by Diagnosis

\begin{tabular}{|c|c|c|c|c|c|}
\hline & $\begin{array}{l}\text { Normal } \\
(n=48)\end{array}$ & $\begin{array}{l}\text { High risk } \\
(n=48)\end{array}$ & $\begin{array}{c}\text { Depressed } \\
(n=55)\end{array}$ & Statistic & $p$ \\
\hline Age (years) & I5.2(I.4) & I5.0(।.5) & $15.3(1.4)$ & 0.38 & NS \\
\hline Male & $19(39.6)$ & $21(43.7)$ & $23(41.8)$ & & \\
\hline Female & $29(60.4)$ & $27(56.3)$ & $32(58.2)$ & & \\
\hline African-American & $6(12.5)$ & $7(14.6)$ & $6(10.9)$ & & \\
\hline Asian-American & $10(20.8)$ & $8(16.7)$ & $9(16.4)$ & & \\
\hline Caucasian & $23(47.9)$ & $23(47.9)$ & $29(52.7)$ & & \\
\hline Hispanic & $9(18.8)$ & $10(20.8)$ & I| (20.0) & & \\
\hline CGAS score & $83.2(9.7)^{\mathrm{a}}$ & $78.9(10.0)^{\mathrm{a}}$ & $50.7(7.4)^{b}$ & 202.37 & 0.0001 \\
\hline Smoked cigarettes ever (\%) & $8(16.7)$ & $9(18.8)$ & $14(25.5)$ & 1.35 & NS \\
\hline Current smokers (\%) & $4(8.3)$ & $4(8.3)$ & $7(12.7)$ & 0.76 & NS \\
\hline FTQ score ${ }^{b}$ & $1.4(0.5)$ & I.I (0.5) & $1.3(0.6)$ & 0.31 & NS \\
\hline Stress score & $3.4(2.9)^{\mathrm{a}}$ & $3.7(3.0)^{\mathrm{a}}$ & $6.0(5.5)^{b}$ & 6.54 & 0.002 \\
\hline Salivary cortisol $(\mathrm{ng} / \mathrm{ml})^{c}$ & $0.4(0.2)$ & $0.5(0.3)$ & $0.5(0.3)$ & 0.75 & NS \\
\hline $\operatorname{NUFC}(\mathrm{ng} / \mathrm{ml})^{c}$ & $15.6(7.9)^{\mathrm{a}}$ & $21.2(\mid 3.1)^{a, b}$ & $21.9(11.4)^{b}$ & 3.72 & 0.03 \\
\hline Total NUFC ${ }^{c}$ & $8.3(4.1)^{\mathrm{a}}$ & $10.8(6.1)^{a, b}$ & $11.7(5.8)^{b}$ & 4.57 & 0.02 \\
\hline Anxiety disorder & - & - & $19(34.5)$ & - & - \\
\hline Disruptive disorder & - & - & $7(12.7)$ & - & - \\
\hline
\end{tabular}

Abbreviations: CGAS, children's global assessment scale; FTQ, Fagerström Tolerance Questionnaire; NUFC, nocturnal urinary free cortisol.

aHigher score is associated with higher socioeconomic status (Hollingshead scale).

bIncludes only current smokers.

'Analysis was performed on transformed data.

Data are presented as means or raw numbers; data in parentheses reflect standard deviations or percentages.

Different subscripts denote significant differences among groups.

initiation (see Figure 1). Among adolescents who experienced high stress levels in combination with elevated HPA activity, $53.3 \%$ were likely to initiate smoking in comparison with $3.0 \%$ of youngsters in the low HPA activity-low stress category (Mantel-Cox $\chi^{2}=20.35, \mathrm{df}=3, p=0.0001$ ). Among youth in the low HPA activity-high stress group, $35.0 \%$ were likely to smoke during the follow-up period compared with $24.1 \%$ in the high HPA activity-low stress group.

When HPA activity and stressful experiences were tested as predictors of nicotine dependence symptoms, only HPA activity was significant (std. $\beta=0.70, \mathrm{CI}=0.54-1.67$, $t=4.11, \quad p=0.001 ; \quad$ adjusted $\quad R^{2}=0.43, \quad \mathrm{~F}_{2,18}=8.43$, $p=0.003)$.

\section{Persistence of Smoking}

At intake, 31 adolescents reported prior smoking history. Of these, $19(61.3 \%)$ youth also reported smoking during follow-up (persistent smokers). Adolescents who persisted with smoking during follow-up did not differ significantly from abstainers on any demographic or clinical variables (see Table 4). There was, however, a trend for persistent smokers to experience higher stress at baseline compared with abstainers. The mean FTQ score in the smokers was 4.2 $(\mathrm{SD}=1.5$; range, 1.5-7.0). On the basis of the FTQ score, 1 (5.3\%) persistent smoker showed no evidence of nicotine dependence, 14 (73.7\%) had moderate level of dependence and four $(21.1 \%)$ manifested high level of dependence.

Of a total of 14 depressed youth with prior smoking history at intake, $4 / 5(80.0 \%)$ adolescents with comorbid anxiety disorder persisted with smoking during follow-up in comparison with 5/9 (55.6\%) participants without anxiety disorder (FET, NS). Also, 2/2 (100.0\%) youth with comorbid disruptive disorder persisted with smoking compared with 7/12 (58.3\%) without disruptive disorder (FET, NS).

\section{Effects of HPA Activity and Stress on Persistent Smoking}

There was a trend for adolescents who reported smoking at the time of intake (current smokers; $n=15$ ) to have higher HPA activity compared with past smokers $(0.8 \pm 1.1$ vs $0.2 \pm 0.9, t_{29}=1.72, p=0.10$ ). After controlling for smoking status and magnitude of stress at the time intake, elevated HPA activity (higher evening/night-time cortisol levels) was 
Table 2 Demographic and Clinical Parameters in Adolescents Who Reported no Prior Smoking History at Intake, Stratified on Smoking Initiation During Follow-up

\begin{tabular}{|c|c|c|c|c|}
\hline & $\begin{array}{l}\text { Never } \\
\text { smoked } \\
(n=88)\end{array}$ & $\begin{array}{l}\text { Initiated } \\
\text { smoking } \\
(n=2 I)\end{array}$ & Statistic & $p$ \\
\hline Age & $14.9(1.3)$ & | $4.8(1.5)$ & 0.49 & NS \\
\hline Gender & & & 0.01 & NS \\
\hline Male & $37(42.0)$ & $9(42.9)$ & & \\
\hline Female & $51(58.0)$ & $12(57.1)$ & & \\
\hline Ethnicity & & & 0.33 & NS \\
\hline Caucasian & $40(45.5)$ & II (52.4) & & \\
\hline Non-Caucasian & $48(54.5)$ & $10(47.6)$ & & \\
\hline Socioeconomic score ${ }^{a}$ & $44.5(10.7)$ & $44.0(12.6)$ & 0.18 & NS \\
\hline Follow-up interval (years) & $3.5(1.1)$ & $4.0(0.9)$ & 1.84 & 0.07 \\
\hline Diagnosis at baseline & & & 1.41 & NS \\
\hline Normal & $32(36.4)$ & $5(23.8)$ & & \\
\hline High risk & $28(31.8)$ & $7(33.3)$ & & \\
\hline Depression & $28(31.8)$ & $9(42.9)$ & & \\
\hline Hamilton depression rating scale & $7.0(9.3)$ & $9.0(9.7)$ & 0.88 & NS \\
\hline Beck depression inventory & $8.4(10.2)$ & $7.6(8.7)$ & 0.30 & NS \\
\hline Children's global assessment scale & $71.7(16.8)$ & $70.1(18.9)$ & 0.38 & NS \\
\hline Stressful life experiences & $3.9(3.6)$ & $5.1(5.5)$ & 1.20 & 0.09 \\
\hline
\end{tabular}

aHigher score is associated with higher socioeconomic status (Hollingshead scale).

Data are presented as means or raw numbers; data in parentheses reflect standard deviations or percentages.

Table 3 Cox Regression Model Predicting Initiation of Smoking in Adolescents Who had no Prior Smoking History at Intake

\begin{tabular}{lcrcc}
\hline & $\boldsymbol{\beta}(\mathbf{S E})$ & Wald & OR (CI) & P \\
\hline HPA activity & & & & \\
Stress at follow-up & $1.26(0.26)$ & 23.78 & $3.54(2.15-5.84)$ & 0.000 I \\
HPA activity $\times$ stress & $0.09(0.25)$ & 0.02 & $1.09(0.67-1.78)$ & NS \\
at follow-up & & & & \\
\hline
\end{tabular}

Abbreviations: SE, standard error; OR, odds ratio; $\mathrm{Cl}$, confidence interval; HPA, hypothalamic-pituitary-adrenal.

${ }^{a} \mathrm{HPA}$ activity (a composite measure of evening/night-time cortisol levels). $\chi^{2}=37.79, \mathrm{df}=3, p=9.0001$.

associated with persistence of smoking during follow-up (see Table 5). Stressful experiences did not significantly influence persistent smoking. After accounting for the effects of smoking status and magnitude of stress at intake, HPA activity (evening/night-time cortisol levels) made a significant contribution to nicotine dependence symptoms in persistent smokers $\left(R^{2}\right.$ change $=0.31, \quad \mathrm{~F}_{3,15}=3.84$, $p=0.03$ ). The analyses were run separately in depressed adolescents, and the same pattern emerged even after controlling for comorbid disorders. Among controls, stressful experiences moderated the effect of HPA activity (evening/night-time cortisol levels) on persistent smoking in such a way that the effect of elevated HPA activity (higher evening/night-time cortisol levels) on the likelihood of persistent smoking was reduced under conditions of low stress $\left(\beta_{\mathrm{e}}=0.19, \mathrm{CI}=0.05-0.71, p=0.02\right)$.

\section{Relationship between Smoking and Depression during Follow-up}

Among control subjects, 6/22 (27.3\%) smokers developed a major depressive episode during follow-up compared with $8 / 67$ (11.9\%) non-smokers (Fisher's exact test, $p=0.10$ ). Of the six participants with both depression and smoking history, five subjects initiated smoking first and a depressive episode preceded smoking in one participant. Within the depressed group, 12/18 (61.1\%) adolescents who reported smoking during follow-up developed a recurrent depressive episode compared with $9 / 33(27.3 \%)$ youth with no smoking history $\left(\chi^{2}=5.60, p=0.02\right)$. Of the 12 youngsters with both depression and smoking history, smoking preceded recurrent depressive episode in seven subjects and smoking initiation followed a recurrent depressive episode in five.

To examine whether the relationship between smoking and depression was accounted, in part, by HPA activity (evening/night-time cortisol levels) and stressful experiences, all three diagnostic groups were combined. Smoking during follow-up predicted depressive disorder $\left(\beta_{\mathrm{e}}=3.61\right.$, $\left.\mathrm{CI}=1.60-8.16, p=0.002 ; \chi^{2}=9.49, p=0.002\right)$. When HPA activity (evening/night-time cortisol levels) and stressful experiences were included in the model, the effect of smoking on depression was reduced $\left(\beta_{\mathrm{e}}=1.28, \mathrm{CI}=0.46\right.$ 3.56, NS; $\left.\delta \chi^{2}=14.47, p=0.001\right)$.

\section{DISCUSSION}

To the best of our knowledge, this is the first study to integrate neurobiological and psychosocial factors in evaluating vulnerability factors for cigarette smoking in depressed and non-depressed adolescents. The findings indicate that both evening/night-time cortisol values and stressful life experiences are associated with increased risk for smoking in adolescents. It is noteworthy that higher evening/night-time cortisol values were observed before the onset of smoking in a subset of adolescents, and that stressful life experiences showed additive effects on the risk for smoking. In addition, higher evening/night-time cortisol values were associated with persistent smoking in youth who had prior smoking history. Smoking was also associated with increased frequency of depressive episodes.

Prior research has revealed that nicotine affects the HPA axis, possibly through interactions with nicotinic acetylcholine receptors (Berlin, 2009; Brenner et al, 1986; Chen et al, 2008; Markou, 2008; Rohleder and Kirschbaum, 2006; Sidhartha et al, 2009). In addition, studies in animals have shown that corticotropin-releasing factor and corticosteroids increase self-administration of nicotine, possibly by reducing sensitivity of the brain to the effects of nicotine, and thereby increasing the quantities of nicotine needed to elicit a particular response (Bruijnzeel et al, 2007; Caggiula et al, 1998; O'Dell and Khroyan, 2009; Pauly et al, 1990a; Zislis et al, 2007). Stress also increases the onset and relapse 


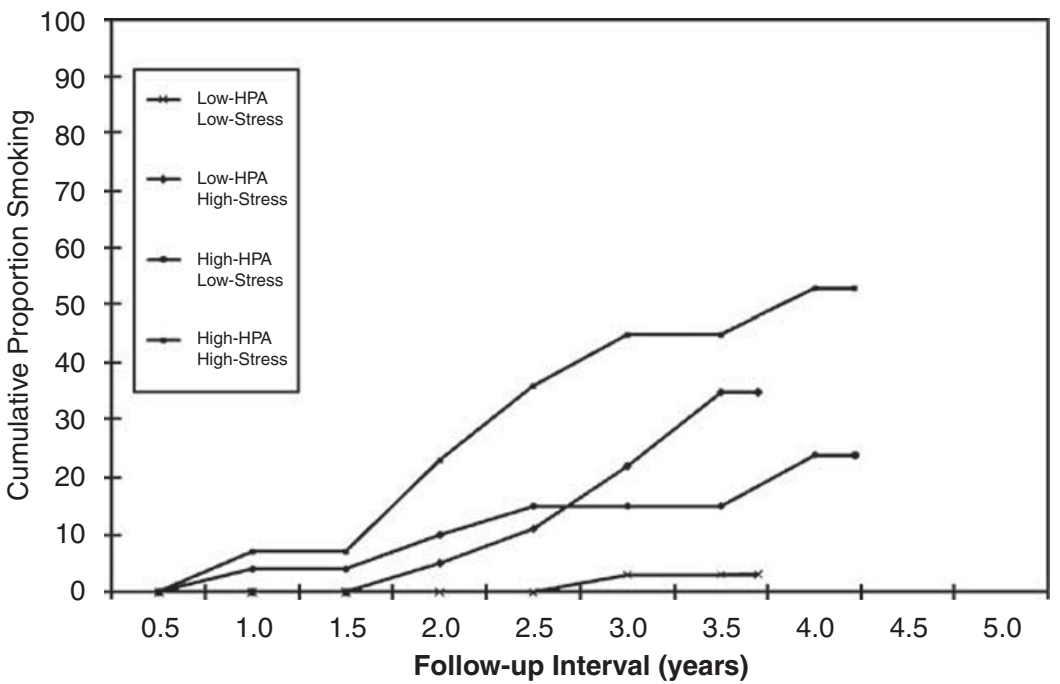

Figure I Probability of smoking during follow-up in adolescents who reported no prior smoking history at intake, stratified on HPA activity (a composite measure of evening/night-time cortisol levels) measured at baseline and stressful experiences at follow-up.

Table 4 Demographic and Clinical Parameters in Adolescents who Reported Prior Smoking History at Intake, Stratified on Smoking Status During Follow-up

\begin{tabular}{|c|c|c|c|c|}
\hline & $\begin{array}{l}\text { Abstain } \\
\text { from } \\
\text { smoking } \\
(n=12)\end{array}$ & $\begin{array}{l}\text { Persist } \\
\text { with } \\
\text { smoking } \\
(n=19)\end{array}$ & Statistic & $p$ \\
\hline Age & I5.4(।.6) & I5.5 (।.5) & 0.19 & NS \\
\hline Gender & & & 0.10 & NS \\
\hline Male & $5(4 I .7)$ & $9(47.4)$ & & \\
\hline Female & $7(58.3)$ & $10(52.6)$ & & \\
\hline Ethnicity & & & 0.78 & NS \\
\hline Caucasian & $7(58.3)$ & $8(42.1)$ & & \\
\hline Non-Caucasian & $5(41.7)$ & II (57.9) & & \\
\hline Socioeconomic score ${ }^{a}$ & $45.3(12.0)$ & $42.0(11.1)$ & 0.77 & NS \\
\hline Follow-up interval (years) & $3.7(0.8)$ & $3.7(1.1)$ & 0.05 & NS \\
\hline Diagnosis at baseline & & & 0.59 & NS \\
\hline Normal & $4(33.3)$ & $4(21.1)$ & & \\
\hline High risk & $3(25.0)$ & $6(31.6)$ & & \\
\hline Depression & $5(4 I .7)$ & $9(47.4)$ & & \\
\hline Hamilton depression rating scale & $8.8(9.5)$ & $9.2(9.4)$ & 0.11 & NS \\
\hline Beck depression inventory & $9.1(8.1)$ & $9.5(8.4)$ & 0.13 & NS \\
\hline Children's global assessment scale & $68.1(16.1)$ & $62.9(15.6)$ & 0.89 & NS \\
\hline Stressful life experiences & $3.1(4.1)$ & $5.3(2.9)$ & 1.77 & 0.09 \\
\hline
\end{tabular}

aHigher score is associated with higher socioeconomic status (Hollingshead scale).

Data are presented as means or raw numbers; data in parentheses reflect standard deviations or percentages.

of smoking behavior in humans (Anda et al, 1999; Bruijnzeel and Gold, 2005; Byrne and Mazanov, 2003; Byrne et al, 1995; Cohen and Lichtenstein, 1990; McCarthy et al,
Table 5 Cox Regression Model Predicting Persistence of Smoking During Follow-up in Adolescents Who had Prior Smoking History at Intake

\begin{tabular}{|c|c|c|c|c|}
\hline & $\beta$ (SE) & Wald & OR (Cl) & $p$ \\
\hline \multicolumn{5}{|l|}{ Model I } \\
\hline $\begin{array}{l}\text { Smoking at intake } \\
\text { (current smoker) }\end{array}$ & $-0.32(0.48)$ & 0.44 & $0.73(0.29-1.86)$ & NS \\
\hline Stress at intake & $0.09(0.06)$ & 2.24 & $1.09(0.97-1.22)$ & NS \\
\hline \multicolumn{5}{|l|}{ Model 2} \\
\hline $\begin{array}{l}\text { Smoking at intake } \\
\text { (current smoker) }\end{array}$ & $0.40(0.57)$ & 0.50 & $1.49(0.49-4.53$ & NS \\
\hline Stress at baseline & $0.09(0.08)$ & 1.27 & $1.09(0.94-1.27)$ & NS \\
\hline HPA activity $^{\mathrm{a}}$ & $0.85(0.33)$ & 6.59 & $2.34(1.22-4.48)$ & 0.01 \\
\hline Stress at follow-up & $0.20(0.18)$ & 1.25 & $1.23(0.86-1.75)$ & NS \\
\hline $\begin{array}{l}\text { HPA activity } \times \text { stress } \\
\text { at follow-up }\end{array}$ & $0.10(0.18)$ & 0.33 & I.I। (0.78-1.56) & NS \\
\hline
\end{tabular}

Abbreviations: SE, standard error; OR, odds ratio; $\mathrm{Cl}$, confidence interval; HPA, hypothalamic-pituitary-adrenal.

aHPA activity (a composite measure of evening/night-time cortisol levels).

Model I: $\chi^{2}=2.45, \mathrm{df}=2, \mathrm{NS} ; \delta \chi^{2}=2.42, \mathrm{df}=2, \mathrm{NS}$.

Model $2: \chi^{2}=15.53, \mathrm{df}=5, p=0.008 ; \delta \chi^{2}=10.80, \mathrm{df}=3, p=0.01$.

2006; Park et al, 2009; Parrott, 1995; Orlando et al, 2001; Perkins and Grobe, 1992; Shapiro et al, 2002). There are, however, individual differences in the magnitude of HPA response to stress, and in the ability of the HPA axis to modulate self-administration of nicotine (Frederick et al, 1998; Kudielka et al, 2009; Pauly et al, 1990b; Piazza et al, 1989; Pomerleau and Pomerleau, 1990; Sarnyai et al, 1998). Our data in adolescents are congruent with these observations in that they showed individual differences in evening/ night-time cortisol levels and their relationship with smoking.

Consistent with earlier reports in adolescents and adults (Breslau et al, 1998; Brown et al, 1996; Choi et al, 1997; Fergusson et al, 2003; Goodman and Capitman, 2000; Patton 
et al, 1998; Windle and Windle, 2001), a high proportion of depressed adolescents exhibited smoking behavior (although not significantly higher than control subjects), and smoking reciprocally increased the risk for development/recurrence of depressive episodes. Evidence suggests that the two conditions might have shared neurobiological substrates (Dursun and Kutcher, 1999; Gamberino and Gold, 1999; Kendler et al, 1993; Markou et al, 1998; Rao and Chen, 2008; Volkow, 2004). In addition to their association with smoking, numerous studies have demonstrated a role of HPA dysregulation and stressful life experiences in relation to depression (Hammen, 2005; Holsboer and Ising, 2008; Meyer et al, 2001; Kendler et al, 1995). In this study, higher evening/night-time cortisol values measured at baseline and stressful experiences during follow-up partially mediated the association between smoking and subsequent depressive episodes. Hence, reports of associations between depression and smoking behaviors might reflect, in part, shared neurobiological and psychosocial factors (Rao et al, 1999, 2000, 2009a).

\section{Limitations}

Several methodological issues should be considered in interpreting these results. The sample sizes were modest, and it is important to replicate these findings in larger cohorts. The participants in the depressed group had moderate to severe depression, and the study findings might not be generalizable to the population of depressed youth in the community. Moreover, there was insufficient power to detect the effect of comorbid disorders on vulnerability to smoking in the depressed cohort. Other studies reported that anxiety and disruptive behavior disorders increase the likelihood of smoking (Breslau et al, 1991; Brown et al, 1996; Johnson et al, 2000; Kendler et al, 1993; Pomerleau et al, 1995; Riggs et al, 1999). Some adolescents already initiated smoking before the cortisol measures were obtained. It is possible that prior nicotine exposure had an influence on cortisol values at least in some youngsters (Frederick et al, 1998; Friedman et al, 1987; Matta et al, 1998; Pomerleau and Pomerleau, 1990; Wilkins et al, 1982). Adolescents who did not manifest smoking behavior at intake, but subsequently initiated smoking, showed higher evening/night-time cortisol values before the onset of smoking compared with non-smokers, suggesting that higher evening/night-time cortisol values might serve as vulnerability markers for smoking behavior.

Careful assessment of the various stages of smoking, also including nicotine dependence, was not performed (Mayhew et al, 2000). In addition, objective measures of nicotine intake were not obtained. Nevertheless, subjective reports indicated that a substantial proportion of smokers manifested at least moderate nicotine dependence. Severity of nicotine dependence symptoms in the current sample was compared with what was observed in other studies (Colby et al, 2000; Prokhorov et al, 1996, 2001). Moreover, other investigations in adolescents demonstrated that frequency and quantity of smoking correlate well with both nicotine dependence symptoms and cotinine levels (Caraballo et al, 2004, 2009; O'Loughlin et al, 2003; Prokhorov et al, 2000; Rubinstein et al, 2007). Regardless, the magnitude of association between HPA activity/stress and different stages of smoking cannot be delineated from this study.

Only evening/night-time cortisol levels were measured as a reflection of HPA activity. Furthermore, the effect of cortisol values on smoking behavior was only modest. The inclusion of other adrenal steroids as well as precursors of cortisol would be a better reflection of the overall HPA activity, and possibly would have contributed a greater variance to vulnerability for smoking (Rasmusson et al, 2006).

Other important variables, such as genetic polymorphisms, temperament, early-life adversity, peer and family influences, and susceptibility to tobacco advertising, which influence the onset and progression of smoking, as well as HPA activity, were not measured (Davies and Soundy, 2009; Kudielka et al, 2009; Mayhew et al, 2000; Nilsson et al, 2009; Moolchan et al, 2000; Pallonen et al, 1998; Rao et al, 2008; Schepis and Rao, 2005). Despite these limitations, the study has several strengths. In addition to the neurobiological and psychosocial assessments, smoking initiation was documented prospectively at least in most of the subjects. Rigorous procedures were used for medical and psychiatric evaluations, and multiple saliva and urinary samples were obtained for HPA status. Moreover, the approach for assessment and coding of stressful life experiences was thorough.

\section{Clinical Implications}

If the finding that higher evening/night-time cortisol levels are associated with increased vulnerability for smoking and/ or development of nicotine dependence is replicated, it will have clinical implications for developing more specific interventions. For example, metyrapone, an inhibitor of corticosteroid synthesis, and antagonists of the corticotropin-releasing hormone $(\mathrm{CRH})$ reduce self-administration of nicotine and other addictive drugs in animals (Bruijnzeel et al, 2007; Fahlke et al, 1994; Piazza et al, 1994; Zislis et al, 2007). Antiglucocorticoid agents and CRH antagonists might have antidepressant properties, and have been tested in humans for the treatment of depression and other psychiatric disorders (Gallagher et al, 2008; Holsboer and Ising, 2008; Seymour et al, 2003). Moreover, bupropion and other antidepressant drugs are effective in reducing smoking in addition to alleviating depressive symptoms (Hajek et al, 2009; Schepis and Rao, 2008; Tonstad, 2002). Data from both clinical and preclinical studies suggest that treatment with most antidepressant agents reduces responsiveness to stress (Duman et al, 1999; Holsboer, 2001).

It will be important to examine whether HPA activity measured before initiating treatment predicts clinical response (Rao et al, 2005). If smokers with increased HPA activity benefit most from treatment with antidepressant drugs, this particular subgroup could be targeted for pharmacological intervention, and thus minimize the unnecessary exposure of other young smokers to psychotropic medications. In addition to HPA activity, stressful experiences contributed to the vulnerability for smoking. Adolescent smokers frequently report stress reduction as a motive for smoking (Dozois et al, 1995; Nichter et al, 1997). The data from this study suggest that such persons might benefit from adjunctive psychosocial interventions, such as 
assertiveness training and cognitive-behavior therapy, aimed to reduce and/or cope with stressful experiences (Schepis and Rao, 2008). Future studies should evaluate the efficacy of pharmacotherapy and various psychosocial interventions, singly and in combination, in smokers stratified on levels of stress.

Several factors influence the onset and developmental progression of smoking. The fact that individuals might begin on the same developmental pathway, but experience different patterns of tobacco use, leaves open the possibility that risk and resilience factors exert their influence on individuals over time (Mayhew et al, 2000). Therefore, to better understand the risk/resiliency factors associated with adolescent smoking, we need to move from simplistic designs to integrated, transactional models. Such approaches will be helpful not only in developing more effective preventive and treatment strategies for youngsters, but also for the treatment of nicotine addiction in adults.

\section{ACKNOWLEDGEMENTS}

This work was supported, in part, by grants DA14037, DA15131, DA17804, DA17805, MH01419, MH62464, and MH68391 from the National Institutes of Health, from the National Alliance for Research on Schizophrenia and Affective Disorders, and by the Sarah M and Charles E Seay Endowed Chair in Child Psychiatry at UT Southwestern Medical Center. Dr London's work on this study was supported by the Katherine $\mathrm{K}$ and Thomas $\mathrm{P}$ Pike Professorship in Addiction Studies at the University of California, Los Angeles. We also thank Ms Lidia Ortiz for administrative and technical support.

\section{DISCLOSURE}

Dr London received support for other research from Phillip Morris, USA. The other authors have no financial conflict of interest.

\section{REFERENCES}

al'Absi M (2006). Hypothalamic-pituitary-adrenocortical responses to psychological stress and risk for smoking relapse. Int $J$ Psychophysiol 59: 218-227.

American Psychiatric Association (1994). Diagnostic and Statistical Manual of Mental Disorders. American Psychiatric Press: Washington, DC.

Anda RF, Croft JB, Felitti VJ, Nordenberg D, Giles WH, Williamson DF et al (1999). Adverse childhood experiences and smoking during adolescence and adulthood. JAMA 282: 1652-1658.

Anda RF, Williamson DF, Escobedo LG, Mast EE, Giovino GA, Remington PL (1990). Depression and the dynamics of smoking. A national perspective. JAMA 264: 1541-1545.

Andreasen NC, Endicott J, Spitzer RL, Winokur G (1977). The family history method using diagnostic criteria. Reliability and validity. Arch Gen Psychiatry 34: 1229-1235.

Beck AT, Ward CH, Mendelson M, Mock J, Erbaugh J (1961). An inventory for measuring depression. Arch Gen Psychiatry 4: $561-571$.

Berlin I (2009). Endocrine and metabolic effects of smoking cessation. Curr Med Res Opin 25: 527-534.

Berlin I, Spreux-Varoquaux O, Said S, Launay JM (1997). Effects of past history of major depression on smoking characteristics, monoamine oxidase-A and -B activities and withdrawal symptoms in dependent smokers. Drug Alcohol Depend 45: 31-37.

Borrelli B, Niaura R, Keuthen NJ, Goldstein MG, DePue JD, Murphy C et al (1996). Development of major depressive disorder during smoking-cessation treatment. J Clin Psychiatry 57: 534-538.

Botello-Harbaum MT, Haynie DL, Iannotti RJ, Wang J, Gase L, Simons-Morton B (2009). Tobacco control policy and adolescent cigarette smoking status in the United States. Nicotine Tobacco Res 11: 875-885.

Brenner T, Mizrachi R, Bodoff M, Weidenfeld J (1986). Evidence that central nicotinic-acetylcholine receptors are involved in the modulation of basal and stress-induced adrenocortical responses. Exp Neurol 94: 735-743.

Breslau N, Johnson EO (2000). Predicting smoking cessation and major depression in nicotine-dependent smokers. Am J Public Health 90: 1122-1127.

Breslau N, Kilbey M, Andreski P (1991). Nicotine dependence, major depression, and anxiety in young adults. Arch Gen Psychiatry 48: 1069-1074.

Breslau N, Kilbey MM, Andreski P (1992). Nicotine withdrawal symptoms and psychiatric disorders: findings from an epidemiologic study of young adults. Am J Psychiatry 149: 464-469.

Breslau N, Peterson EL, Schultz LR, Chilcoat HD, Andreski P (1998). Major depression and stages of smoking. A longitudinal investigation. Arch Gen Psychiatry 55: 161-166.

Brown GW, Harris T (1978). Social Origins of Depression. Tavistock: London.

Brown RA, Lewinsohn PM, Seeley JR, Wagner EF (1996). Cigarette smoking, major depression, and other psychiatric disorders among adolescents. J Am Acad Child Adolesc Psychiatry 35: 1602-1610.

Bruijnzeel AW, Gold MS (2005). The role of corticotropin-releasing factor-like peptides in cannabis, nicotine, and alcohol dependence. Brain Res Brain Res Rev 49: 505-528.

Bruijnzeel AW, Zislis G, Wilson C, Gold MS (2007). Antagonism of CRF receptors prevents the deficit in brain reward function associated with precipitated nicotine withdrawal in rats. Neuropsychopharmacology 32: 955-963.

Byrne DG, Byrne AE, Reinhart MI (1995). Personality, stress and the decision to commence cigarette smoking in adolescence. J Psychosom Res 39: 53-62.

Byrne DG, Mazanov J (2003). Adolescent stress and future smoking behaviour: a prospective investigation. J Psychosom Res 54: 313-321.

Caggiula AR, Donny EC, Epstein LH, Sved AF, Knopf S, Rose C et al (1998). The role of corticosteroids in nicotine's physiological and behavioral effects. Psychoneuroendocrinology 23: $143-159$.

Caraballo RS, Giovino GA, Pechacek TF (2004). Self-reported cigarette smoking vs serum cotinine among US adolescents. Nicotine Tob Res 6: 19-25.

Caraballo RS, Novak SP, Asman K (2009). Linking quantity and frequency profiles of cigarette smoking to the presence of nicotine dependence symptoms among adolescent smokers: findings from the 2004 National Youth Tobacco Survey. Nicotine Tob Res 11: 49-57.

Centers for Disease Control and Prevention (2002). Annual smoking-attributable mortality, years of potential life lost, and economic costs-United States, 1995-1999. MMWR Morb Mortal Wkly Rep 51: 300-303.

Centers for Disease Control and Prevention (2006). Youth Risk Behavior Surveillance-United States. MMWR Morb Mortal Wkly Rep 55(SS-5): 1-108.

Chen H, Fu Y, Sharp BM (2008). Chronic nicotine self-administration augments hypothalamic-pituitary-adrenal responses to mild acute stress. Neuropsychopharmacology 33: 721-730.

Choi WS, Patten CA, Gillin JC, Kaplan RM, Pierce JP (1997). Cigarette smoking predicts development of depressive symptoms among US adolescents. Ann Behav Med 19: 42-50. 
Cohen S, Lichtenstein E (1990). Perceived stress, quitting smoking, and smoking relapse. Health Psychol 9: 466-478.

Colby SM, Tiffany ST, Shiffman S, Niaura RS (2000). Are adolescent smokers dependent on nicotine? A review of the evidence. Drug Alcohol Depend 59(Suppl 1): S83-S95.

Covey LS, Glassman AH, Stetner F (1990). Depression and depressive symptoms in smoking cessation. Compr Psychiatry 31: 350-354.

Covey LS, Glassman AH, Stetner F (1997). Major depression following smoking cessation. Am J Psychiatry 154: 263-265.

Dahl RE, Ryan ND, Puig-Antich J, Nguyen NA, al-Shabbout M, Meyer VA et al (1991). 24-hour cortisol measures in adolescents with major depression: a controlled study. Biol Psychiatry 30: 25-36.

Davies GE, Soundy TJ (2009). The genetics of smoking and nicotine addiction. $S D$ Med Spec No: 43-49.

Dozois DN, Farrow JA, Miser A (1995). Smoking patterns and cessation motivations during adolescence. Int $J$ Addict 30: 1485-1498.

Duman RS, Malberg J, Thome J (1999). Neural plasticity to stress and antidepressant treatment. Biol Psychiatry 46: 1181-1191.

Dursun SM, Kutcher S (1999). Smoking, nicotine and psychiatric disorders: evidence for therapeutic role, controversies and implications for future research. Med Hypotheses 52: 101-109.

Fagerström KO (1978). Measuring degree of physical dependence to tobacco smoking with reference to individualization of treatment. Addict Behav 3: 235-241.

Fahlke C, Hard E, Thomasson R, Engel JA, Hansen S (1994). Metyrapone-induced suppression of corticosterone synthesis reduces ethanol consumption in high-preferring rats. Pharmacol Biochem Behav 48: 977-981.

Fergusson DM, Goodwin RD, Horwood LJ (2003). Major depression and cigarette smoking: results of a 21-year longitudinal study. Psychol Med 33: 1357-1367.

Frank E, Prien RF, Jarrett RB, Keller MB, Kupfer DJ, Lavori PW et al (1991). Conceptualization and rationale for consensus definitions of terms in major depressive disorder. Remission, recovery, relapse, and recurrence. Arch Gen Psychiatry 48: 851-855.

Frederick SL, Reus VI, Ginsberg D, Hall SM, Munoz RF, Ellman G (1998). Cortisol and response to dexamethasone as predictors of withdrawal distress and abstinence success in smokers. Biol Psychiatry 43: 525-530.

Friedman AJ, Ravnikar VA, Barbieri RL (1987). Serum steroid hormone profiles in postmenopausal smokers and nonsmokers. Fertil Steril 47: 398-401.

Gallagher P, Malik N, Newham J, Young AH, Ferrier IN, Mackin P (2008). Antiglucocorticoid treatments for mood disorders. Cochrane Database Syst Rev 23: CD005168.

Gamberino WC, Gold MS (1999). Neurobiology of tobacco smoking and other addictive disorders. Psychiatr Clin North Am 22: 301-312.

Ginsberg D, Hall SM, Reus VI, Muñoz RF (1995). Mood and depression diagnosis in smoking cessation. Exp Clin Psychopharmacol 3: 389-395.

Glassman AH, Covey LS, Stetner F, Rivelli S (2001). Smoking cessation and the course of major depression: a follow-up study. Lancet 357: 1929-1932.

Goodman E, Capitman J (2000). Depressive symptoms and cigarette smoking among teens. Pediatrics 106: 748-755.

Goodyer IM, Park RJ, Herbert J (2001). Psychosocial and endocrine features of chronic first-episode major depression in 8-16 year olds. Biol Psychiatry 50: 351-357.

Goodyer IM, Herbert J, Altham PME (1997). Short-term outcome of major depression: III. A high cortisol/DHEA ratio and subsequent disappointing life events predict persistent depression. Psychol Med 28: 265-273.

Hajek P, Stead LF, West R, Jarvis M, Lancaster T (2009). Relapse prevention interventions for smoking cessation. Cochrane Database Syst Rev 21: CD003999.
Hamilton M (1960). A rating scale for depression. J Neurol Neurosurg Psychiatry 23: 56-62.

Hammen C (2005). Stress and depression. Ann Rev Clin Psychol 1: 293-319.

Hammen C, Brennan PA (2001). Depressed adolescents of depressed and nondepressed mothers: tests of an interpersonal impairment hypothesis. J Consult Clin Psychol 69: 284-294.

Hammen CL, Burge D, Daley SE, Davila J, Paley B, Rudolph KD (1995). Interpersonal attachment cognitions and prediction of symptomatic responses to interpersonal stress. J Abnorm Psychol 104: $436-443$.

Holsboer F (2001). Stress, hypercortisolism and corticosteroid receptors in depression: implications for therapy. J Affect Disord 62: 77-91.

Holsboer F, Ising M (2008). Central CRH system in depression and anxiety-evidence from clinical studies with CRH1 receptor antagonists. Eur J Pharmacol 583: 350-357.

John U, Meyer C, Rumpf HJ, Hapke U (2004). Depressive disorders are related to nicotine dependence in the population but do not necessarily hamper smoking cessation. J Clin Psychiatry 65: 169-176.

Johnson JG, Cohen P, Pine DS, Klein DF, Kasen S, Brook JS (2000). Association between cigarette smoking and anxiety disorders during adolescence and early adulthood. JAMA 284: 2348-2351.

Johnston LD, O’Malley PM, Bachman JG, Schulenberg JE (2009). Monitoring the Future National Results on Adolescent Drug Use: Overview of Key Findings, 2008 (NIH Publication No. 09-7401). National Institute on Drug Abuse: Bethesda, MD.

Kaufman J, Birmaher B, Brent D, Rao U, Flynn C, Moreci P et al (1997). Schedule for affective disorders and schizophrenia for school-age children-present and lifetime version (K-SADS-PL): initial reliability and validity data. J Am Acad Child Adolesc Psychiatry 36: 980-988.

Kaufman J, Birmaher B, Brent D, Rao U, Ryan ND (1996). The Schedule for Affective Disorders and Schizophrenia for Schoolaged Children-Present and Lifetime Versions (K-SADS-PL). Western Psychiatric Institute and Clinics, University of Pittsburgh: Pittsburgh, PA.

Kaufman J, Martin A, King RA, Charney D (2001). Are child-, adolescent-, and adult-onset depression one and the same disorder? Biol Psychiatry 49: 980-1001.

Kendler KS, Kessler RC, Walters EE, MacLean C, Neale MC, Heath AC et al (1995). Stressful life events, genetic liability, and onset of an episode of major depression in women. Am J Psychiatry 152: 833-842.

Kendler KS, Neale MC, MacLean CJ, Heath AC, Eaves LJ, Kessler RC (1993). Smoking and major depression. A causal analysis. Arch Gen Psychiatry 50: 36-43.

Khaled SM, Bulloch A, Exner DV, Patten SB (2009). Cigarette smoking, stages of change, and major depression in the Canadian population. Can J Psychiatry 54: 204-208.

Klungs $\varnothing y r$ O, Nygard JF, Sorensen T, Sandanger I (2006). Cigarette smoking and incidence of first depressive episode: an 11-year, population-based follow-up study. Am J Epidemiol 163: 421-432.

Koob G, Kreek MJ (2007). Stress, dysregulation of drug reward pathways, and the transition to drug dependence. $A m \mathrm{~J}$ Psychiatry 164: 1149-1159.

Koval JJ, Pederson LL, Mills CA, McGrady GA, Carvajal SC (2000). Models of the relationship of stress, depression, and other psychosocial factors to smoking behavior: a comparison of a cohort of students in grades 6 and 8. Prev Med 30: 463-477.

Kudielka BM, Hellhammer DH, Wust S (2009). Why do we respond so differently? Reviewing determinants of human salivary cortisol responses to challenge. Psychoneuroendocrinology 34: 2-18.

Lopez AD, Mathers CD, Ezzati M, Jamison DT, Murray CJL (2006). The Global Burden of Disease and Risk Factors. The International Bank for Reconstruction and Development/The World Bank \& New York: Oxford University Press, Washington, DC. 
Lovallo WR (2006). Cortisol secretion patterns in addiction and addiction risk. Int J Psychophysiol 59: 195-202.

Markou A (2008). Review. Neurobiology of nicotine dependence. Philos Trans R Soc Lond B Biol Sci 363: 3159-3168.

Markou A, Kosten TR, Koob GF (1998). Neurobiological similarities in depression and drug dependence: a self-medication hypothesis. Neuropsychopharmacology 18: 135-174.

Matta SG, Fu Y, Valentine JD, Sharp BM (1998). Response of the hypothalamo-pituitary-adrenal axis to nicotine. Psychoneuroendocrinology 23: 103-113.

Max W (2001). The financial impact of smoking on health-related costs: a review of the literature. Am J Health Promot 15: 321-331.

Mayhew KP, Flay BR, Mott JA (2000). Stages in the development of adolescent smoking. Drug Alcohol Depend 59(Suppl 1): S61-S81.

McCarthy DE, Piasecki TM, Fiore MC, Baker TB (2006). Life before and after quitting smoking: an electronic diary study. J Abnorm Psychol 115: 454-466.

McCracken JT, Poland RE (1989). Saliva and serum cortisol dynamics following intravenous dexamethasone in normal volunteers. Life Sci 45: 1781-1785.

Mendelson JH, Goletiani N, Sholar MB, Siegel AJ, Mello NK (2008). Effects of smoking successive low- and high-nicotine cigarettes on hypothalamic-pituitary-adrenal axis hormones and mood in men. Neuropsychopharmacology 33: 749-760.

Meyer SE, Chrousos GP, Gold PW (2001). Major depression and the stress system: a life span perspective. Dev Psychopathol 13: 565-580.

Moolchan ET, Ernst M, Henningfield JE (2000). A review of tobacco smoking in adolescents: treatment implications. J Am Acad Child Adolesc Psychiatry 39: 682-693.

Munafò MR, Hitsman B, Rende R, Metcalfe C, Niaura R (2008). Effects of progression to cigarette smoking on depressed mood in adolescents: evidence from the National Longitudinal Study of Adolescent Health. Addiction 103: 162-171.

Nichter M, Vuckovic N, Quintero G, Ritenbaugh C (1997). Smoking experimentation and initiation among adolescent girls: qualitative and quantitative findings. Tob Control 6: 285-295.

Nilsson KW, Oreland L, Kronstrand R, Leppert J (2009). Smoking as a product of gene-environment interaction. Ups J Med Sci 114: 100-107.

O'Dell LE, Khroyan TV (2009). Rodent models of nicotine reward: what do they tell us about tobacco abuse in humans? Pharmacol Biochem Behav 91: 481-488.

O'Loughlin J, DiFranza J, Tyndale RF, Meshefedjian G, McMillanDavey E, Clarke PB et al (2003). Nicotine-dependence symptoms are associated with smoking frequency in adolescents. Am J Prev Med 25: 219-225.

Orlando M, Ellickson PL, Jinnett K (2001). The temporal relationship between emotional distress and cigarette smoking during adolescence and young adulthood. J Consult Clin Psychol 69: 959-970.

Pallonen UE, Prochaska JO, Velicer WF, Prokhorov AV, Smith NF (1998). Stages of acquisition and cessation for adolescent smoking: an empirical integration. Addict Behav 23: 303-324.

Park ER, Chang Y, Quinn V, Regan S, Cohen L, Viguera A et al (2009). The association of depressive, anxiety, and stress symptoms and postpartum relapse to smoking: a longitudinal study. Nicotine Tob Res 11: 707-714.

Parrott AC (1995). Stress modulation over the day in cigarette smokers. Addiction 90: 233-244.

Patton GC, Carlin JB, Coffey C, Wolfe R, Hibbert M, Bowes G (1998). Depression, anxiety, and smoking initiation: a prospective study over 3 years. Am J Public Health 88: 1518-1522.

Pauly JR, Grun EU, Collins AC (1990a). Chronic corticosterone administration modulates nicotine sensitivity and brain nicotinic receptor binding in $\mathrm{C} 3 \mathrm{H}$ mice. Psychopharmacology (Berl) 101: $310-316$.
Pauly JR, Ullman EA, Collins AC (1990b). Strain differences in adrenalectomy-induced alterations in nicotine sensitivity in the mouse. Pharmacol Biochem Behav 35: 171-179.

Paykel E, Mangen S (1980). Interview for Recent Life Events. St George's Hospital Medical School. Department of Psychiatry: London.

Perkins KA, Grobe JE (1992). Increased desire to smoke during acute stress. $\mathrm{Br} J$ Addict 87: 1037-1040.

Piazza PV, Deminiere JM, Le Moal M, Simon H (1989). Factors that predict individual vulnerability to amphetamine self-administration. Science 245: 1511-1513.

Piazza PV, Marinelli M, Jodogne C, Deroche V, Rouge-Pont F, Maccari S et al (1994). Inhibition of corticosterone synthesis by Metyrapone decreases cocaine-induced locomotion and relapse of cocaine self-administration. Brain Res 658: 259-264.

Poland RE, Rubin RT (1982). Saliva cortisol levels following dexamethasone administration in endogenously depressed patients. Life Sci 30: 177-181.

Pomerleau OF, Downey KK, Stelson FW, Pomerleau CS (1995). Cigarette smoking in adult patients diagnosed with attention deficit hyperactivity disorder. J Subst Abuse 7: 373-378.

Pomerleau OF, Pomerleau CS (1990). Cortisol response to a psychological stressor and/or nicotine. Pharmacol Biochem Behav 36: 211-213.

Prokhorov AV, De Moor C, Pallonen UE, Hudmon KS, Koehly L, Hu S (2000). Validation of the modified Fagerstrom tolerance questionnaire with salivary cotinine among adolescents. Addict Behav 25: 429-433.

Prokhorov AV, Hudmon KS, de Moor CA, Kelder SH, Conroy JL, Ordway N (2001). Nicotine dependence, withdrawal symptoms, and adolescents' readiness to quit smoking. Nicotine Tob Res 3: 151-155.

Prokhorov AV, Pallonen UE, Fava JL, Ding L, Niaura R (1996). Measuring nicotine dependence among high-risk adolescent smokers. Addict Behav 21: 117-127.

Rao U, Chen LA (2008). Neurobiological and psychosocial processes associated with depressive and substance-related disorders in adolescents. Current Drug Abuse Rev 1: 68-80.

Rao U, Chen LA (2009). Characteristics, correlates, and outcomes of childhood and adolescent depressive disorders. Dialogues Clin Neurosci 11: 45-62.

Rao U, Dahl RE, Ryan ND, Birmaher B, Williamson DE, Giles DE et al (1996). The relationship between longitudinal clinical course and sleep and cortisol changes in adolescent depression. Biol Psychiatry 40: 474-484.

Rao U, Daley SE, Hammen C (2000). Relationship between depression and substance use disorders in adolescent women during the transition to adulthood. J Am Acad Child Adolesc Psychiatry 39: 215-222.

Rao U, Hammen C, Ortiz LR, Chen LA, Poland RE (2008). Effects of early and recent adverse experiences on adrenal response to psychosocial stress in depressed adolescents. Biol Psychiatry 64: 521-526.

Rao U, Hammen CL, Poland RE (2009a). Mechanisms underlying the comorbidity between depressive and addictive disorders in adolescents: interactions between stress and HPA activity. Am J Psychiatry 166: 361-369.

Rao U, Hammen CL, Poland RE (2009b). Risk markers for depression in adolescents: sleep and HPA measures. Neuropsychopharmacology 34: 1936-1945.

Rao U, Ott GE, Lin KM, Gertsik L, Poland RE (2005). Effect of bupropion on nocturnal urinary free cortisol and its association with antidepressant response. J Psychiatr Res 39: 183-190.

Rao U, Ryan ND, Dahl RE, Birmaher B, Rao R, Williamson DE et al (1999). Factors associated with the development of substance use disorder in depressed adolescents. J Am Acad Child Adolesc Psychiatry 38: 1109-1117.

Rasmusson AM, Wu R, Paliwal P, Anderson GM, Krishna-Sarin S (2006). A decrease in the plasma DHEA to cortisol ratio during 
smoking abstinence may predict relapse: a preliminary study. Psychopharmacology 186: 473-480.

Riggs PD, Mikulich SK, Whitmore EA, Crowley TJ (1999). Relationship of ADHD, depression, and non-tobacco substance use disorders to nicotine dependence in substance-dependent delinquents. Drug Alcohol Depend 54: 195-205.

Rohleder N, Kirschbaum C (2006). The hypothalamic-pituitaryadrenal (HPA) axis in habitual smokers. Int J Psychophysiol 59: 236-243.

Rubinstein ML, Thompson PJ, Benowitz NL, Shiffman S, Moscicki $A B$ (2007). Cotinine levels in relation to smoking behavior and addiction in young adolescent smokers. Nicotine Tob Res 9: 129-135.

Sarnyai Z, Dhabhar FS, McEwen BS, Kreek MJ (1998). Neuroendocrine-related effects of long-term, 'binge' cocaine administration: diminished individual differences in stress-induced corticosterone response. Neuroendocrinology 68: 334-344.

Schepis TS, Rao U (2005). Epidemiology and etiology of adolescent smoking. Curr Opin Pediatr 17: 607-612.

Schepis TS, Rao U (2008). Smoking cessation for adolescents: a review of pharmacological and psychosocial treatments. Current Drug Abuse Rev 1: 142-154.

Seymour PA, Schmidt AW, Schulz DW (2003). The pharmacology of CP-154,526, a non-peptide antagonist of the CRH1 receptor: a review. CNS Drug Rev 9: 57-96.

Shaffer D, Gould MS, Brasic J, Ambrosini P, Fisher P, Bird H et al (1983). A children's global assessment scale (CGAS). Arch Gen Psychiatry 40: 1228-1231.

Shapiro D, Jamner LD, Davydov DM, James P (2002). Situations and moods associated with smoking in everyday life. Psychol Addict Behav 16: 342-345.

Shapiro R, Keller M (1979). Longitudinal Interval Follow-Up Evaluation (LIFE). Massachusetts General Hospital: Boston.

Shapiro SS, Wilk MB (1965). An analysis of variance test for normality (complete samples). Biometrika 52: 591-611.

Sidhartha T, Poland RE, Rao U (2009). Effects of smoking on hormones, brain, and behavior. In: Pfaff DW, Arnold AP,
Etgen AM, Fahrbach SE, Rubin RT (eds). Hormones, Brain and Behavior 2nd edn, Vol 5. Academic Press: San Diego. pp 3337-9962.

Sinha R (2008). Chronic stress, drug use, and vulnerability to addiction. Ann N Y Acad Sci 1141: 105-130.

Siqueira L, Diab M, Bodian C, Rolnitzky L (2000). Adolescents becoming smokers: the roles of stress and coping methods. J Adolesc Health 27: 399-408.

Steuber TL, Danner F (2006). Adolescent smoking and depression: which comes first? Addict Behav 31: 133-136.

Thompson WD, Orvaschel H, Prusoff BA, Kidd KK (1982). An evaluation of the family history method for ascertaining psychiatric disorders. Arch Gen Psychiatry 39: 53-58.

Tonstad S (2002). Use of sustained-release bupropion in specific patient populations for smoking cessation. Drugs 62(Suppl 2): 37-43.

Tsoh JY, Humfleet GL, Munoz RF, Reus VI, Hartz DT, Hall SM (2000). Development of major depression after treatment for smoking cessation. Am J Psychiatry 157: 368-374.

Volkow ND (2004). The reality of comorbidity: depression and drug abuse. Biol Psychiatry 56: 714-717.

Wilkins JN, Carlson HE, Van Vunakis H, Hill MA, Gritz E, Jarvik ME (1982). Nicotine from cigarette smoking increases circulating levels of cortisol, growth hormone, and prolactin in male chronic smokers. Psychopharmacology (Berl) 78: 305-308.

Windle M, Windle RC (2001). Depressive symptoms and cigarette smoking among middle adolescents: prospective associations and intrapersonal and interpersonal influences. J Consult Clin Psychol 69: 215-226.

Zislis G, Desai TV, Prado M, Shah HP, Bruijnzeel AW (2007). Effects of the CRF receptor antagonist D-Phe CRF(12-41) and the alpha2-adrenergic receptor agonist clonidine on stressinduced reinstatement of nicotine-seeking behavior in rats. Neuropharmacology 53: 958-966. 